Published in final edited form as:

Heart Rhythm. 2010 April ; 7(4): 549-558. doi:10.1016/j.hrthm.2009.12.006.

\title{
J Wave Syndromes
}

Charles Antzelevitch, PhD, FHRS ${ }^{1}$ and Gan-Xin Yan, MD, PhD $2,3,4$

${ }^{1}$ Masonic Medical Research Laboratory, Utica, NY, USA.

${ }^{2}$ Main Line Health Heart Center and Lankenau Institute for Medical Research, Wynnewood, PA, USA.

${ }^{3}$ Jefferson Medical College, Philadelphia, PA, USA.

${ }^{4}$ The First Affiliated Hospital, Medical School of Xi'an Jiaotong University, Xi'an, China

\section{Abstract}

The $\mathrm{J}$ wave, also referred to as an Osborn wave, is a deflection immediately following the QRS complex of the surface ECG. When partially buried in the R wave, the J wave appears as a J point elevation or ST segment elevation. Several lines of evidence have been advanced suggesting that arrhythmias associated with early repolarization (ER) pattern in the inferior leads or mid- to lateral precordial leads, Brugada syndrome $(\mathrm{BrS})$ as well arrhythmias associated with hypothermia and the acute phase of ST segment elevation myocardial infarction (STEMI), are mechanistically linked to abnormalities in the manifestation of the transient outward current $\left(\mathrm{I}_{\mathrm{to}}\right)$-mediated $\mathrm{J}$ wave. Although $\mathrm{BrS}$ and early repolarization syndrome (ERS) differ with respect to the magnitude and lead location of abnormal $\mathbf{J}$ wave manifestation, they can be considered to represent a continuous spectrum of phenotypic expression that we propose be termed $\mathbf{J}$ wave syndromes. This review attempts to summarize our current state of knowledge concerning J-wave syndromes, bridging basic and clinical aspects. We propose to divide ERS into three subtypes: Type 1, displaying an ER pattern predominantly in the lateral precordial leads, is prevalent among healthy male athletes and rarely seen in VF survivors; Type 2, displaying an ER pattern predominantly in the inferior or infero-lateral leads, is associated with a higher level of risk; whereas Type 3, displaying an ER pattern globally in the inferior, lateral and right precordial leads, is associated with the highest level of risk for development of malignant arrhythmias and is often associated with VF storms.

\section{Keywords}

Cardiac arrhythmias; Sudden cardiac death; Sudden cardiac arrest; Transient outward current; J point elevation; Early repolarization syndrome; Brugada syndrome; Idiopathic Ventricular fibrillation; Hypothermia; STEMI

(C) 2009 The Heart Rhythm Society. Published by Elsevier Inc. All rights reserved.

Address for correspondence: Charles Antzelevitch, PhD, FHRS, Executive Director and Director of Research, Gordon K. Moe Scholar, Masonic Medical Research Laboratory, 2150 Bleecker Street, Utica, NY 13501, Phone: (315)735-2217, FAX: (315)735-5648, ca@mmrl.edu.

Publisher's Disclaimer: This is a PDF file of an unedited manuscript that has been accepted for publication. As a service to our customers we are providing this early version of the manuscript. The manuscript will undergo copyediting, typesetting, and review of the resulting proof before it is published in its final citable form. Please note that during the production process errors may be discovered which could affect the content, and all legal disclaimers that apply to the journal pertain.

Conflicts of Interest: There are no conflicts of interest to disclose. 


\section{Introduction}

The J point denotes the junction of the QRS complex and the ST segment on the electrocardiogram (ECG), marking the end of depolarization and beginning of repolarization. The J wave, also referred to as the Osborn wave, in recognition of Osborn's landmark description in the early 1950s, 1 is a deflection with a dome or hump morphology in the same direction as the R wave, immediately following the QRS complex of the surface ECG. The clinical and arrhythmogenic significance of $\mathbf{J}$ wave abnormalities were largely ignored until a report in 1996 elucidating the ionic and cellular basis of $\mathbf{J}$ wave and pointing out its potential role in life-threatening tachyarrhythmias. 2 Several lines of evidence have since been advanced suggesting that arrhythmias associated with an early repolarization (ER) pattern in the inferior or mid- to lateral precordial leads (i.e. classically defined early repolarization pattern), Brugada syndrome (BrS) and some cases of idiopathic ventricular fibrillation (IVF) with the ER pattern in the inferior, infero-lateral or global leads as well as arrhythmias associated with hypothermia and the acute phase of ST segment elevation myocardial infarction (STEMI), are mechanistically linked to abnormalities in the manifestation of the transient outward current $\left(\mathrm{I}_{\mathrm{to}}\right.$ )-mediated $\mathrm{J}$ wave.

Although BrS and early repolarization syndrome (ERS) differ with respect to the magnitude and lead location of abnormal $\mathrm{J}$ wave manifestation, they can be considered to represent a continuous spectrum of phenotypic expression that we have proposed be termed $\mathbf{J}$ wave syndromes. ${ }^{3-} 7$ This review attempts to summarize our current state of knowledge concerning $\mathrm{J}$-wave syndromes, bridging basic and clinical aspects.

\section{Historical Perspective of $\mathbf{J}$ wave and $\mathbf{J}$ wave-related Clinical Phenomena}

In 1938, Tomashewski et al. provided the first description of hypothermic J wave in an accidentally frozen man. He described the $\mathrm{J}$ wave as a very slowly inscribed deflection between the QRS complex and the ST segment of the ECG. ${ }^{8}$ In 1953, Osborn described what he called a "current of injury" in dogs that were acidotic and hypothermic that fibrillated at rectal temperatures less than $25^{\circ} \mathrm{C} .{ }^{1}$ This so called "current of injury" was later named the Osborn wave. ${ }^{9}$

An ER pattern on the ECG was first described in 1936 by Shipley and Hallaran. They evaluated the four-lead electrocardiogram of two hundred healthy young men and women and described $\mathrm{J}$ deflection as slurring or notching of the terminal part of QRS complex and considered it as a normal variant. ${ }^{10}$ This electrocardiographic phenomenon was ascribed to accelerated ventricular repolarization with $2 \%$ prevalence in healthy adults. In 1961, Wasserburger and co-workers further defined ER as an elevated take-off of the ST segment at the J junction of the QRS complex varying from 1 to $4 \mathrm{~mm}$ from isoelectric line accompanied by downward concavity of the ST segment and symmetrically limbed T wave often of large amplitude in mid to left precordial leads. ${ }^{11}$ In subsequent years, several investigators sought to characterize the clinical importance of the electrocardiographic ER pattern and failed to find any immediate and long term consequences. ${ }^{12}$

A shift away from a benign view of the J wave began in 1984 when Otto and co-workers presented three cases of ventricular fibrillation that occurred during sleep in young males of Southeast Asian refugees who had structurally normal hearts. The only prominent electrocardiographic abnormality in these patients was a prominent $\mathbf{J}$ wave accompanied by ST segment elevation. ${ }^{13}$ In the Philippine capital city, Malina, a total of 722 apparently healthy young males died during sleep from 1948 to 1982 from a disease then called "Bangungut" (to rise and moan during sleep) in their native language. ${ }^{14}$ In the 1980s, the US Center for Disease Control received approximately 120 case reports of sudden cardiac death in Southeast Asian refugees living in the United States who were apparently healthy.15 Similar cases of IVF in 
which the ECGs exhibited prominent $\mathrm{J}$ waves in the inferior leads were reported by Aizawa et al.16, 17

In 1992, Pedro and Josep Brugada published a landmark study describing eight sudden cardiac death patients in whom the ECG revealed "right bundle branch block" and ST segment elevation in the precordial leads V1 to V3, without obvious structural heart diseases.18 In 1996, we and others named this entity "Brugada syndrome" (BrS).2, 19 In many cases of BrS the "right bundle branch block" (RBBB) appears without an S wave in the left precordial leads, suggesting that in these cases the RBBB is apparent and that the R' represents an accentuation of the $\mathrm{J}$ wave. A consensus report published in 2002 delineated diagnostic criteria for the syndrome. A second consensus conference report, published in 2005, focused on risk stratification schemes and approaches to therapy.20

In 1999, Gussak and Antzelevitch suggested that in some cases ER may be malignant, based on observations that an ER pattern in arterially-perfused wedge preparations can easily convert to one in which phase 2 reentry gives rise to polymorphic VT/VF. ${ }^{3}$ Evidence in support of this hypothesis was provided by Kalla et al., ${ }^{21}$ and Takagi et al. ${ }^{22}$ in 2000 . They reported ventricular fibrillation in patients with prominent $\mathrm{J}$ wave and ST-segment elevation in inferior leads without structural heart diseases and postulated that IVF with ER pattern in inferior leads may represent a variant of the BrS. In 2008, Haissaguerre ${ }^{23}$ and $\mathrm{Nam}^{7}$ demonstrated a definitive association between $\mathbf{J}$ waves with ER pattern and ventricular fibrillation. All of these clinical observations have suggested a critical role for the $\mathrm{J}$ wave in the pathogenesis of many different forms of IVF. $5,21,24-27$

\section{Ionic and Cellular Mechanisms for the $\mathbf{J}$ wave and Associated Arrhythmogenesis}

Since the 1980s, work from our group first proposed that transmural differences in early phases of the action potential (phases 1 and 2) are responsible for inscription of the electrocardiographic $\mathrm{J}$ wave. ${ }^{28,} 29$ The ventricular epicardium commonly displays action potentials with a prominent $\mathrm{I}_{\mathrm{to}}$-mediated notch or spike and dome. A prominent $\mathrm{I}_{\mathrm{to}_{\mathrm{o}}}$-mediated action potential notch in ventricular epicardium but not endocardium produces a transmural voltage gradient during early ventricular repolarization that registers as a $\mathbf{J}$ wave or $\mathbf{J}$ point elevation on the ECG. Direct evidence in support of this hypothesis was obtained in arteriallyperfused canine ventricular wedge preparations in $1996^{2}$ and is presented in detail in Figure 1.

Factors that influence $\mathrm{I}_{\mathrm{to}}$ kinetics or ventricular activation sequence can modify the manifestation of the J wave on the ECG. For example, because of its slow recovery from inactivation, $\mathrm{I}_{\mathrm{to}}$ is reduced following an acceleration of heart rate, resulting in a decrease in the magnitude of the $\mathrm{J}$ wave. ${ }^{30,} 31$

An increase in net repolarizing current, due either to a decrease of inward currents or augmentation of outward currents, accentuates the notch leading to augmentation of the $J$ wave or appearance of ST segment elevation. A further increase in net repolarizing current can result in partial or complete loss of the action potential dome, leading to a transmural voltage gradient that manifests as greater ST segment elevation. ${ }^{30-32}$ This was the first compelling evidence that the ST segment elevation can occur in the absence of myocardial ischemia. In regions of the myocardium exhibiting a prominent $\mathrm{I}_{\mathrm{to}}$, such as the epicardium of right ventricle, marked accentuation of the action potential notch results in a transmural voltage gradient that leads to coved ST segment elevation, which is the only form of ST segment elevation diagnostic of $\mathrm{BrS}$ (Fig. 2B). A further outward shift of the currents active during the early phase of the action potential can lead to loss of the action potential dome, thus creating a dispersion of 
repolarization between epicardium and endocardium as well as within epicardium, between the region where the dome is lost and regions at which it is maintained (Fig. 2C).

Because accentuation of the action potential notch and loss of the dome are due to an outward shift of currents secondary to either a decrease in inward currents $\left(\mathrm{I}_{\mathrm{Na}}\right.$ and $\left.\mathrm{I}_{\mathrm{Ca}}\right)$ or an increase in outward potassium currents, sodium channel blockers like procainamide, pilsicainide, propafenone, flecainide and disopyramide can be used to induce or unmask ST segment elevation in patients with concealed J-wave syndromes. ${ }^{33-35}$ Sodium channel blockers like quinidine, which also inhibits $\mathrm{I}_{\text {to }}$, reduce the magnitude of the $\mathrm{J}$ wave and normalize $\mathrm{ST}$ segment elevation. 32,36

The degree of accentuation of the action potential notch leading to loss of the dome depends on the magnitude of $\mathrm{I}_{\mathrm{to}} \cdot 31,32,37$ When $\mathrm{I}_{\text {to }}$ is prominent, as it is in the right ventricular epicardium, ${ }^{31,} 32,38$ an outward shift of current causes phase 1 of the action potential to progress to more negative potentials at which the L-type calcium current $\left(\mathrm{I}_{\mathrm{Ca}, \mathrm{L}}\right)$ fails to activate, leading to an all-or-none repolarization and loss of the dome (Fig 2C). Loss of the action potential dome is usually heterogeneous, resulting in marked abbreviation of action potential at some sites but not others. The dome can then propagate from regions where it is maintained to regions where it is lost, giving rise to a very closely coupled extrasystole via a mechanism that we have termed phase 2 reentry (Fig. 2D). ${ }^{39}$ The extrasystole produced via phase 2 reentry often occurs on the preceding $\mathrm{T}$ wave resulting in an $\mathrm{R}$-on- $\mathrm{T}$ phenomenon. This in turn can initiate polymorphic ventricular tachycardia (VT) or ventricular fibrillation (Figs. 2E and F).

An outward shift of current that extends beyond the action potential notch can not only accentuate the $\mathrm{J}$ wave but also lead to depression of the dome. Activation of the ATP-sensitive potassium current $\left(\mathrm{I}_{\mathrm{K}-\mathrm{ATP}}\right)$ or depression of inward calcium channel current $\left(\mathrm{I}_{\mathrm{Ca}}\right)$ can effect such a change (Figs. 3A and B). This is more likely to manifest in the ECG as an ER pattern consisting of a J point elevation, slurring of the terminal part of the QRS and mild ST segment elevation. The ER pattern can facilitate loss of the dome due to other factors and thus lead to the development of ST segment elevation, phase 2 reentry and VT/VF. In the presence of relatively large $\mathrm{I}_{\text {to }}$, commonly seen in $\mathrm{RV}$ epicardium, the same shift of current responsible for ER pattern in LV may cause phase 2 reentry and VT/VF (Fig. 3C and D).

Figure 4 illustrates the congruence of the arrhythmic mechanisms highlighted above with the electrocardiographic manifestations of a clinical case of IVF in which prominent $J$ waves in lead II precede the development of VT/VF. ${ }^{17}$

\section{Clinical and ECG features of J-Wave Syndromes}

J wave syndromes can be inherited or acquired (Table 1). The clinical and ECG features of inherited $\mathrm{J}$ wave syndromes may co-exist in an individual patient or among members of the same family. For example, Qi et al., ${ }^{27}$ reported a young Chinese man with recurrent VF who had prominent $\mathbf{J}$ waves and ST segment elevation in almost all ECG leads, displaying the ECG attributes of all of these syndromes (Figure 5). Also, in a family reported by Takagi et al., one patient with recurrent syncope and inducible VF displayed ER in the inferior leads; whereas his brother had a typical Brugada-like ECG pattern with ST segment elevation in the right precordial leads. ${ }^{40} \mathrm{SCN} 5 \mathrm{~A}$ mutations have been associated with ST segment elevation in the right precordial leads as well as the inferior leads. ${ }^{41,42}$

\section{The Brugada Syndrome}

The BrS, a clinical entity described by Josep and Pedro Brugada in 1992, is associated with high risk of VF. ${ }^{18}$ The ECG features of the Brugada patient includes an accentuated $\mathrm{J}$ wave 
imitating incomplete right branch bundle block (RBBB) and ST segment elevation in the right precordial leads $\left(\mathrm{V}_{1}-\mathrm{V}_{3}\right){ }^{18,19}$

As one of the $\mathrm{J}$ wave syndromes, the ECG characteristics and clinical outcomes of the $\mathrm{BrS}$ are dictated by the ionic and cellular mechanism responsible for the manifestation of the epicardial action potential notch: ST-segment elevation in BrS patients is influenced by heart rate and autonomic tone ${ }^{19}$ and its coved morphology, which represents a highly accentuated epicardial action potential notch that can readily result in loss of the epicardial action potential dome, is associated with a higher incidence of sudden cardiac death.

$\mathrm{BrS}$ has been associated with mutations in seven different genes. Mutations in $S C N 5 \mathrm{~A}$ $\left(\mathrm{Na}_{\mathrm{v}} 1.5, \mathrm{BrS} 1\right)$ have been reported in $11-28 \%$ of $\mathrm{BrS}$ probands, CACNA1C $\left(\mathrm{Ca}_{\mathrm{v}} 1.2, \mathrm{BrS} 3\right)$ in $6.7 \%, C A C N B 2 b\left(\mathrm{Ca}_{\mathrm{v}} \beta 2 \mathrm{~b}, \mathrm{BrS} 4\right)$ in $4.8 \%$ and mutations in Glycerol-3-phophate dehydrogenase 1-like enzyme gene (GPDIL, BrS2), SCNIB ( $\beta_{1}$-subunit of sodium channel, BrS5), KCNE3 (MiRP2; BrS6) and SCN3B ( $\beta 3$-subunit of sodium channel, BrS7) are much more rare. ${ }^{43-} 50$ These genetic defects lead to either a loss of function of sodium $\left(\mathrm{I}_{\mathrm{Na}}\right)$ or $\mathrm{L}$ type calcium $\left(\mathrm{I}_{\mathrm{Ca}}\right)$ channel current, or a gain of function of transient outward current $\left(\mathrm{I}_{\mathrm{to}}\right)$. Approximately $60-70 \%$ of $\mathrm{BrS}$ probands remain genotype-negative.

\section{The Early Repolarization and Idiopathic Ventricular Fibrillation}

The ER pattern has long been considered to be a "benign" ECG manifestation that is more commonly seen in young healthy men and athletes. ${ }^{11,31,51}$ However, there is mounting evidence that the ER pattern may be associated with a risk of VF, depending on the ER location, magnitude of J wave and degree of ST elevation. ${ }^{7,21,23}$ A number of cases previously labeled as IVF, particularly in Asian males, display a prominent $\mathbf{J}$ wave and ER specifically limited to the inferior leads or globally to the inferior, lateral and right precordial leads. ${ }^{13}, 16,17,21,52$

The most comprehensive study to date evaluating the prevalence and prognostic significance of ER in a community-based general population of 10,864 middle- aged subjects ( $44 \pm 8 \mathrm{y} / \mathrm{o})$, concluded that an ER pattern in the inferior leads is associated with an increased risk of death from cardiac causes in middle-aged subjects. J point elevation of $>0.1 \mathrm{mV}$ in the inferior leads was present in $3.5 \%$, in the lateral leads in $2.4 \%$ and in both in $0.1 \%$. J-point elevation of $>0.1$ $\mathrm{mV}$ in inferior leads was associated with an increased risk of death from cardiac causes (adjusted relative risk, $1.28 \mathrm{P}=0.03$ ). J-point elevation $>0.2 \mathrm{mV}$ in inferior leads was observed in $0.3 \%$ and increased the adjusted relative risk of death from cardiac causes to $2.98(\mathrm{P}<0.001)$. 53

We propose to divide ERS into three subtypes (Table 1): Type 1 is associated with ER pattern predominantly in the lateral precordial leads; this form is very prevalent among healthy male athletes and is rarely seen in VF survivors. Type 2 displays an ER pattern predominantly in the inferior or infero-lateral leads and is associated with a higher level of risk; numerous cases of otherwise idiopathic VF have this electrocardiographic pattern, ${ }^{21,23}$ which is also prevalent in healthy young males. Type 3 displays an ER pattern globally in the inferior, lateral and right precordial leads and is associated with the highest level of risk for the development of malignant arrhythmias; it is often associated with VF storms. ${ }^{7,} 27$

The ST segment elevation responsible for the ER pattern is thought to be generated by depression of the epicardial action potential dome ${ }^{31}$, which by itself may not be sufficient to give rise to repolarization heterogeneities necessary for the development of reentrant tachycardia. The outward shift in the balance of current responsible for the ER pattern may nevertheless facilitate the development of phase 2 reentry and polymorphic VT/VF in the presence of other provocative forces. A weaker $\mathrm{I}_{\text {to }}$ permits a partial loss of the epicardial action potential dome in the left ventricular lateral free wall epicardium that manifests as the ER in 
lateral precordial leads. ${ }^{31}$ Because only mild to moderate action potential shortening occurs under these conditions, phase 2 reentry unlikely occurs. However, in the presence of a more intense $\mathrm{I}_{\mathrm{to}}$, as typically found in the right ventricle, or with a greater outward shift of current in the left ventricle, all-or-none repolarization can occur, giving rise to phase 2 reentry and VT/ VF (Fig. 3 and Fig. 4).

The arrhythmic potential of a global ER pattern, particularly ER in inferior leads, was suggested by several clinical reports ${ }^{21}, 27,54$ and highlighted in recent studies by Haissaguerre et al. and Nam et al.. ${ }^{7}, 55$ Haissaguerre and co-workers compared 206 case subjects with IVF to 412 healthy control subjects ${ }^{23}$ and demonstrated that an ER pattern was more prevalent in subjects with IVF. ${ }^{23}$ Patients with IVF who had the ER pattern were more likely to experience syncope or cardiac arrest during sleep than those without the ER pattern. Additionally, they were able to map the site of origin of ectopic activity in 8 patients and found that the origin of ectopy was consistent with the location of the repolarization abnormality in ECG. A definitive association between ER and IVF was therefore presented in this report by Haissaguerre and co-workers ${ }^{23}$ as well as in an adjoining report by Nam and co-workers ${ }^{7}$ and a subsequent report from Viskin's group. ${ }^{52}$

Nam et al. ${ }^{55}$ reported that global accentuation of $\mathbf{J}$ waves across the precordial and limb leads identifies a subgroup of patients with ER who have a highly arrhythmogenic substrate. A shortlong-short sequence and extrasystoles with short coupling intervals were more frequently observed in ER patients compared to those with BrS. These electrocardiographic features were found to presage the occurrence of VF storms (Figure 6). ${ }^{55}$

The observations noted above suggest that the substrate and trigger responsible for the development of malignant arrhythmias associated with ER or BrS are similar. Some ECG characteristics of ERS also closely match ECG features of BrS, including the dynamic nature, accentuated $\mathbf{J}$ waves, pause and bradycardia-dependence, short coupled extrasystole-induced polymorphic VT/VF. Suppression of the ECG features by isoproterenol or pacing in ER patients further supports the notion that they share common underlying electrophysiologic abnormalities with BrS patients. ${ }^{55}$ However, salient diagnostic features of $\mathrm{BrS}$ such as provocation by sodium channel blockers or positive signal averaged ECG are rarely observed in these IVF patients. ${ }^{7,55}$

The genetic basis for ER is not well defined. Consistent with the findings that $\mathrm{I}_{\mathrm{K}-\mathrm{ATP}}$ activation can generate an ER pattern in canine ventricular wedge preparations, a rare variant in $\mathrm{KCNJ} 8$, responsible for the pore forming subunit of the $\mathrm{I}_{\mathrm{K}-\mathrm{ATP}}$ channel, has recently been reported in a patient with ERS; expression studies are not available as yet. ${ }^{56}$ Preliminary reports by our group have also identified loss of function mutations in the $\alpha 1$ and $\beta 2$ subunits of the cardiac L-type calcium channel in patients with ERS. ${ }^{57}$

Like most cases of Brugada syndrome and ERS1, bradycardia accentuates ST segment elevation, and tachycardia tends to normalize the ST segment in the ERS type 2 or type 3. VF often occurs near midnight or in the early morning hours when heart rate is slower and parasympathetic tone is augmented. ${ }^{21,27}$ Preliminary reports have also identified loss of function mutations in the L-type calcium channel in patients with these forms of ERS. ${ }^{57}$

Hypothermia-The appearance of a prominent J wave in the ECG is considered pathognomonic of hypothermia; they may manifest diffusely in all leads or be confined to selected leads. Rarely, hypothermia can induce ECG changes that mimic BrS. ${ }^{58}$

Profound hypothermia can lead to the development of VF. In dogs with profound hypothermia (reduction of body temperature by 5 to $10 \mathrm{C}^{\circ}$ ), intravenous infusion of quinidine, which inhibits 
$\mathrm{I}_{\mathrm{to}}$, is effective in preventing VF. ${ }^{59}$ However, it seems that there is no significant gender dominance in appearance of hypothermia-induced VF (Table 1).

VF in the Acute Phase of ST Segment Elevation Myocardial Infarction (STEMI) - There are a number of similarities between the ECG and clinical features of acute myocardial ischemia and those of ERS and BrS. ${ }^{13}, 21,27,32,60-62$ Prominent $\mathrm{J}$ waves in the ECG have been reported to occur in association with acute myocardial ischemia. ${ }^{63,} 64$

Clinical observations suggest an association between $\mathrm{I}_{\text {to }}$ density and risk of primary VF during acute myocardial infarction (MI). For example, women with coronary heart disease have only a quarter of the risk for sudden cardiac death as compared to men. ${ }^{65}$ This may be due, in part, to a more prominent $\mathrm{I}_{\mathrm{to}}$ in males versus females, which is thought to be responsible for the predominance of $\mathbf{J}$ wave syndromes in men (Table 1). ${ }^{66}$ Similarly, the incidence of primary VF is higher in patients with acute inferior MI who have right ventricular involvement $(8.4 \%)$ than those without $(2.7 \%)$, or with an anterior MI $(5.0 \%){ }^{67}$ This may be due to the fact that $\mathrm{I}_{\mathrm{to}}$ is much more prominent in right vs. left ventricular epicardium. ${ }^{38,68}$

Taken together, these observations suggest that the fundamental mechanisms responsible for ST segment elevation and the initiation of VF are similar in the early phases of acute myocardial ischemia and the inherited $\mathbf{J}$ wave syndromes in which phase 2 reentry functions as a trigger and enhanced dispersion of repolarization as reentry substrate for the development of VF. ${ }^{69}$

\section{J Wave Syndromes}

Because of the similarity in ECG characteristics, clinical outcomes, risk factors and the fact that these syndromes and entities share a common arrhythmic platform related to amplification of $\mathrm{I}_{\mathrm{to}}$-mediated $\mathbf{J}$ waves, we consider it appropriate to group these congenital and acquired syndromes and entities under the heading of $\mathbf{J}$ wave syndromes (Table 1$){ }^{3-7}$

Our working hypothesis is that an outward shift in repolarizing current due to a decrease in sodium or calcium channel currents or an increase in $\mathrm{I}_{\mathrm{to}}, \mathrm{I}_{\mathrm{K}-\mathrm{ATP}}, \mathrm{I}_{\mathrm{K}-\mathrm{ACh}}$, or other outward currents can give rise to $\mathrm{J}$ wave syndromes, which includes BrS, ERS, hypothermia-and STEMI-induced VF (Fig. 7 and Table 1). The particular phenotype depends on what part of the heart is principally affected and which ion channels are involved. We view the $\mathrm{J}$ wave syndromes as a spectrum of disorders that involve accentuation of the epicardial action potential notch in different regions of heart, leading to the development of prominent $\mathbf{J}$ waves that reflect at the body surface the substrate for development of phase 2 reentry and VT/VF.

\section{Acknowledgments}

Supported by HL47678 from NHLBI (CA), Masons of New York State and Florida (CA), the Sharpe-Strumia Research Foundation (GXY) and the Albert M. Greenfield Foundation (GXY)

\section{References}

1. Osborn JJ. Experimental hypothermia: respiratory and blood $\mathrm{pH}$ changes in relation to cardiac function. Am J Physiol 1953;175:389-398. [PubMed: 13114420]

2. Yan GX, Antzelevitch C. Cellular basis for the electrocardiographic J wave. Circulation 1996;93:372379. [PubMed: 8548912]

3. Gussak I, Antzelevitch C. Early repolarization syndrome: clinical characteristics and possible cellular and ionic mechanisms. J Electrocardiol 2000;33:299-309. [PubMed: 11099355]

4. Yan GX, Yao QH, Wang DQ, Cui CC. Electrocardiographic J wave and J wave syndromes. Chin J Cardiac Arrhyth 2004;8:360-365. 
5. Shu J, Zhu T, Yang L, Cui C, Yan GX. ST-segment elevation in the early repolarization syndrome, idiopathic ventricular fibrillation, and the Brugada syndrome: cellular and clinical linkage. J Electrocardiol 2005;38:26-32. [PubMed: 16226071]

6. Hlaing T, Dimino T, Kowey PR, Yan GX. ECG repolarization waves: their genesis and clinical implications. Ann Noninvasive Electrocardiol 2005;10:211-223. [PubMed: 15842434]

7. Nam GB, Kim YH, Antzelevitch C. Augmentation of J waves and electrical storms in patients with early repolarization. N Engl J Med 2008;358:2078-2079. [PubMed: 18463391]

8. Tomaszewski W. Changement electrocardiographiques observes chez un homme mort de froid. Arch Mal Coeur Vaiss 1938;31:525-528.

9. Abbott JA, Cheitlin MD. The nonspecific camel-hump sign. JAMA 1976;235:413-414. [PubMed: 946087]

10. Shipley RA, Hallaran WR. The four lead electrocardiogram in 200 normal men and women. Am Heart J 1936;11:325-345.

11. Wasserburger RH, Alt WJ. The normal RS-T segment elevation variant. Am J Cardiol 1961;8:184192. [PubMed: 13783301]

12. Kambara H, Phillips J. Long-term evaluation of early repolarization syndrome (normal variant RST segment elevation). Am J Cardiol 1976;38:157-161. [PubMed: 133604]

13. Otto CM, Tauxe RV, Cobb LA, et al. Ventricular fibrillation causes sudden death in Southeast Asian immigrants. Ann Intern Med 1984;101:45-47. [PubMed: 6732093]

14. Munger RG, Booton EA. Bangungut in Manila: sudden and unexplained death in sleep of adult Filipinos. Int J Epidemiol 1998;27:677-684. [PubMed: 9758125]

15. Centers for Disease Control (CDC). Sudden, unexpected, nocturnal deaths among Southeast Asian refugees. MMWR Morb Mortal Wkly Rep 1981;30:581-584. [PubMed: 6796814]

16. Aizawa Y, Tamura M, Chinushi M, et al. An attempt at electrical catheter ablation of the arrhythmogenic area in idiopathic ventricular fibrillation. Am Heart J 1992;123:257-260. [PubMed: 1729844]

17. Aizawa $\mathrm{Y}$, Tamura M, Chinushi M, et al. Idiopathic ventricular fibrillation and bradycardia-dependent intraventricular block. Am Heart J 1993;126:1473-1474. [PubMed: 8249808]

18. Brugada P, Brugada J. Right bundle branch block, persistent ST segment elevation and sudden cardiac death: a distinct clinical and electrocardiographic syndrome: a multicenter report. J Am Coll Cardiol 1992;20:1391-1396. [PubMed: 1309182]

19. Miyazaki T, Mitamura H, Miyoshi S, Soejima K, Aizawa Y, Ogawa S. Autonomic and antiarrhythmic drug modulation of ST segment elevation in patients with Brugada syndrome. J Am Coll Cardiol 1996;27:1061-1070. [PubMed: 8609322]

20. Antzelevitch C, Brugada P, Borggrefe M, et al. Brugada syndrome: report of the second consensus conference: endorsed by the Heart Rhythm Society and the European Heart Rhythm Association. Circulation 2005;111:659-670. [PubMed: 15655131]

21. Kalla H, Yan GX, Marinchak R. Ventricular fibrillation in a patient with prominent J (Osborn) waves and ST segment elevation in the inferior electrocardiographic leads: a Brugada syndrome variant? J Cardiovasc Electrophysiol 2000;11:95-98. [PubMed: 10695469]

22. Takagi M, Aihara N, Takaki H, et al. Clinical characteristics of patients with spontaneous or inducible ventricular fibrillation without apparent heart disease presenting with J wave and ST segment elevation in inferior leads. J Cardiovasc Electrophysiol 2000;11:844-848. [PubMed: 10969745]

23. Haissaguerre M, Derval N, Sacher F, et al. Sudden cardiac arrest associated with early repolarization. N Engl J Med 2008;358:2016-2023. [PubMed: 18463377]

24. Geller JC, Reek S, Goette A, Klein HU. Spontaneous episode of polymorphic ventricular tachycardia in a patient with intermittent Brugada syndrome. J Cardiovasc Electrophysiol 2001;12:1094. [PubMed: 11573705]

25. Komiya N, Imanishi R, Kawano H, et al. Ventricular fibrillation in a patient with prominent J wave in the inferior and lateral electrocardiographic leads after gastrostomy. PACE 2006;29:1022-1024. [PubMed: 16981930]

26. Riera AR, Ferreira C, Schapachnik E, Sanches PC, Moffa PJ. Brugada syndrome with atypical ECG: downsloping ST-segment elevation in inferior leads. J Electrocardiol 2004;37:101-104. [PubMed: 15127375] 
27. Qi X, Sun F, An X, Yang J. A case of Brugada syndrome with ST segment elevation through entire precordial leads. Chin J Cardiol 2004;32:272-273.

28. Litovsky SH, Antzelevitch C. Transient outward current prominent in canine ventricular epicardium but not endocardium. Circ Res 1988;62:116-126. [PubMed: 2826039]

29. Antzelevitch C, Sicouri S, Litovsky SH, et al. Heterogeneity within the ventricular wall. Electrophysiology and pharmacology of epicardial, endocardial, and M cells. Circ Res 1991;69:1427-1449. [PubMed: 1659499]

30. Antzelevitch C, Yan GX. Cellular and ionic mechanisms responsible for the Brugada syndrome. J Electrocardiol 2000;33:33-39. [PubMed: 11265734]

31. Yan GX, Lankipalli RS, Burke JF, Musco S, Kowey PR. Ventricular repolarization components on the electrocardiogram: cellular basis and clinical significance. J Am Coll Cardiol 2003;42:401-409. [PubMed: 12906963]

32. Yan GX, Antzelevitch C. Cellular basis for the Brugada syndrome and other mechanisms of arrhythmogenesis associated with ST segment elevation. Circulation 1999;100:1660-1666. [PubMed: 10517739]

33. Shimizu W, Antzelevitch C, Suyama K, et al. Effect of sodium channel blockers on ST segment, QRS duration, and corrected QT interval in patients with Brugada syndrome. J Cardiovasc Electrophysiol 2000;11:1320-1329. [PubMed: 11196553]

34. Brugada R, Brugada J, Antzelevitch C, et al. Sodium channel blockers identify risk for sudden death in patients with ST-segment elevation and right bundle branch block but structurally normal hearts. Circulation 2000;101:510-515. [PubMed: 10662748]

35. Morita H, Morita ST, Nagase S, et al. Ventricular arrhythmia induced by sodium channel blocker in patients with Brugada syndrome. J Am Coll Cardiol 2003;42:1624-1631. [PubMed: 14607450]

36. Gussak I, Antzelevitch C, Bjerregaard P, Towbin JA, Chaitman BR. The Brugada syndrome: clinical, electrophysiologic and genetic aspects. J Am Coll Cardiol 1999;33:5-15. [PubMed: 9935001]

37. Antzelevitch, C.; Shimizu, W.; Yan, GX. Electrical heterogeneity and the development of arrhythmias. In: Olsson, SB.; Yuan, S.; Amlie, JP., editors. Dispersion of Ventricular Repolarization: State of the Art. Armonk, NY: Futura Publishing Company, Inc.; 2000. p. 3-21.

38. Di Diego JM, Sun ZQ, Antzelevitch C. $I_{\text {to }}$ and action potential notch are smaller in left vs. right canine ventricular epicardium. Am J Physiol 1996;271:H548-H561. [PubMed: 8770096]

39. Krishnan SC, Antzelevitch C. Flecainide-induced arrhythmia in canine ventricular epicardium. Phase 2 reentry? Circulation 1993;87:562-572. [PubMed: 8425300]

40. Matsuo K, Shimizu W, Kurita T, et al. Increased dispersion of repolarization time determined by monophasic action potentials in two patients with familial idiopathic ventricular fibrillation. J Cardiovasc Electrophysiol 1998;9:74-83. [PubMed: 9475580]

41. Potet F, Mabo P, Le Coq G, et al. Novel Brugada SCN5A mutation leading to ST segment elevation in the inferior or the right precordial leads. J Cardiovasc Electrophysiol 2003;14:200-203. [PubMed: 12693506]

42. Takehara N, Makita N, Kawabe J, et al. A cardiac sodium channel mutation identified in Brugada syndrome associated with atrial standstill. J Intern Med 2004;255:137-142. [PubMed: 14687250]

43. Chen Q, Kirsch GE, Zhang D, et al. Genetic basis and molecular mechanisms for idiopathic ventricular fibrillation. Nature 1998;392:293-296. [PubMed: 9521325]

44. Schulze-Bahr E, Eckardt L, Breithardt G, et al. Sodium channel gene (SCN5A) mutations in 44 index patients with Brugada syndrome: different incidences in familial and sporadic disease. Hum Mutat 2003;21:651-652. [PubMed: 14961552]

45. London B, Michalec M, Mehdi H, et al. Mutation in glycerol-3-phosphate dehydrogenase 1 like gene (GPD1-L) decreases cardiac $\mathrm{Na}^{+}$current and causes inherited arrhythmias. Circulation 2007;116:2260-2268. [PubMed: 17967977]

46. Antzelevitch C, Pollevick GD, Cordeiro JM, et al. Loss-of-function mutations in the cardiac calcium channel underlie a new clinical entity characterized by ST-segment elevation, short QT intervals, and sudden cardiac death. Circulation 2007;115:442-449. [PubMed: 17224476]

47. Watanabe H, Koopmann TT, Le Scouarnec S, et al. Sodium channel b1 subunit mutations associated with Brugada syndrome and cardiac conduction disease in humans. J Clin Invest 2008;118:22602268. [PubMed: 18464934] 
48. Delpón E, Cordeiro JM, Núñez L, et al. Functional effects of $K C N E 3$ mutation and its role in the development of Brugada syndrome. Circ Arrhythm Electrophysiol 2008;1:209-218. [PubMed: 19122847]

49. Hu D, Barajas-Martinez H, Burashnikov E, et al. A mutation in the b3 subunit of the cardiac sodium channel associated with Brugada ECG phenotype. Circ Cardiovasc Genet 2009;2:270-278. [PubMed: 20031595]

50. Kapplinger JD, Wilde AAM, Antzelevitch C, et al. A worldwide compendium of putative Brugada syndrome associated mutations in the SCN5A encoded cardiac sodium channel. Heart Rhythm 2009;6:S392.

51. Mehta MC, Jain AC. Early repolarization on scalar electrocardiogram. Am J Med Sci 1995;309:305311. [PubMed: 7771499]

52. Rosso R, Kogan E, Belhassen B, et al. J-point elevation in survivors of primary ventricular fibrillation and matched control subjects: incidence and clinical significance. J Am Coll Cardiol 2008;52:12311238. [PubMed: 18926326]

53. Tikkanen JT, Anttonen O, Junttila MJ, et al. Long-term outcome associated with early repolarization on electrocardiography. N Engl J Med. 2009

54. Letsas KP, Efremidis M, Pappas LK, et al. Early repolarization syndrome: is it always benign? Int J Cardiol 2007;114:390-392. [PubMed: 16574260]

55. Nam GB, Ko KH, Kim J, et al. Mode of onset of ventricular fibrillation in patients with early repolarization pattern vs. Brugada syndrome. Eur Heart J. 2009

56. Haissaguerre M, Chatel S, Sacher F, et al. Ventricular fibrillation with prominent early repolarization associated with a rare variant of KCNJ8/K $\mathrm{ATP}$ channel. J Cardiovasc Electrophysiol 2009;20:9398. [PubMed: 19120683]

57. Burashnikov E, Pfeifer R, Borggrefe M, et al. Mutations in the cardiac L-type calcium channel associated with inherited sudden cardiac death syndromes. Circulation 2009;120:S573.

58. Ansari E, Cook JR. Profound hypothermia mimicking a Brugada type ECG. J Electrocardiol 2003;36:257-260. [PubMed: 12942489]

59. Johnson P, Lesage A, Floyd WL, Young WG Jr, Sealy WC. Prevention of ventricular fibrillation during profound hypothermia by quinidine. Ann Surg 1960;151:490-495. [PubMed: 14407499]

60. Yan GX, Kowey PR. ST segment elevation and sudden cardiac death: from the Brugada syndrome to acute myocardial ischemia. J Cardiovasc Electrophysiol 2000;11:1330-1332. [PubMed: $11196554]$

61. Di Diego JM, Fish JM, Antzelevitch C. Brugada syndrome and ischemia-induced ST-segment elevation. Similarities and differences. J Electrocardiol 2005;38:14-17. [PubMed: 16226068]

62. Haissaguerre M, Sacher F, Nogami A, et al. Characteristics of recurrent ventricular fibrillation associated with inferolateral early repolarization role of drug therapy. J Am Coll Cardiol 2009;53:612-619. [PubMed: 19215837]

63. Shinde R, Shinde S, Makhale C, et al. Occurrence of "J waves" in 12-lead ECG as a marker of acute ischemia and their cellular basis. PACE 2007;30:817-819. [PubMed: 17547622]

64. Jastrzebski M, Kukla P. Ischemic J wave: novel risk marker for ventricular fibrillation? Heart Rhythm 2009;6:829-835. [PubMed: 19467513]

65. Kannel WB, Wilson PW, D'Agostino RB, Cobb J. Sudden coronary death in women. Am Heart J 1998;136:205-212. [PubMed: 9704680]

66. Di Diego JM, Cordeiro JM, Goodrow RJ, et al. Ionic and cellular basis for the predominance of the Brugada syndrome phenotype in males. Circulation 2002;106:2004-2011. [PubMed: 12370227]

67. Mehta SR, Eikelboom JW, Natarajan MK, et al. Impact of right ventricular involvement on mortality and morbidity in patients with inferior myocardial infarction. J Am Coll Cardiol 2001;37:37-43. [PubMed: 11153770]

68. Peschar M, de Swart H, Michels KJ, Reneman RS, Prinzen FW. Left ventricular septal and apex pacing for optimal pump function in canine hearts. J Am Coll Cardiol 2003;41:1218-1226. [PubMed: 12679225]

69. Yan GX, Joshi A, Guo D, et al. Phase 2 reentry as a trigger to initiate ventricular fibrillation during early acute myocardial ischemia. Circulation 2004;110:1036-1041. [PubMed: 15302777] 
70. Lerner DJ, Kannel WB. Patterns of coronary heart disease morbidity and mortality in the sexes: a 26year follow-up of the Framingham population. Am Heart J 1986;111:383-390. [PubMed: 3946178]

71. Every N, Hallstrom A, McDonald KM, et al. Risk of sudden versus nonsudden cardiac death in patients with coronary artery disease. Am Heart J 2002;144:390-396. [PubMed: 12228774]

72. Hu D, Viskin S, Oliva A, et al. A novel mutation in the SCN5A gene associated with arrhythmic storm developing during acute myocardial infarction. Heart Rhythm 2007;4:S148.

73. Fish JM, Antzelevitch C. Role of sodium and calcium channel block in unmasking the Brugada syndrome. Heart Rhythm 2004;1:210-217. [PubMed: 15851155] 

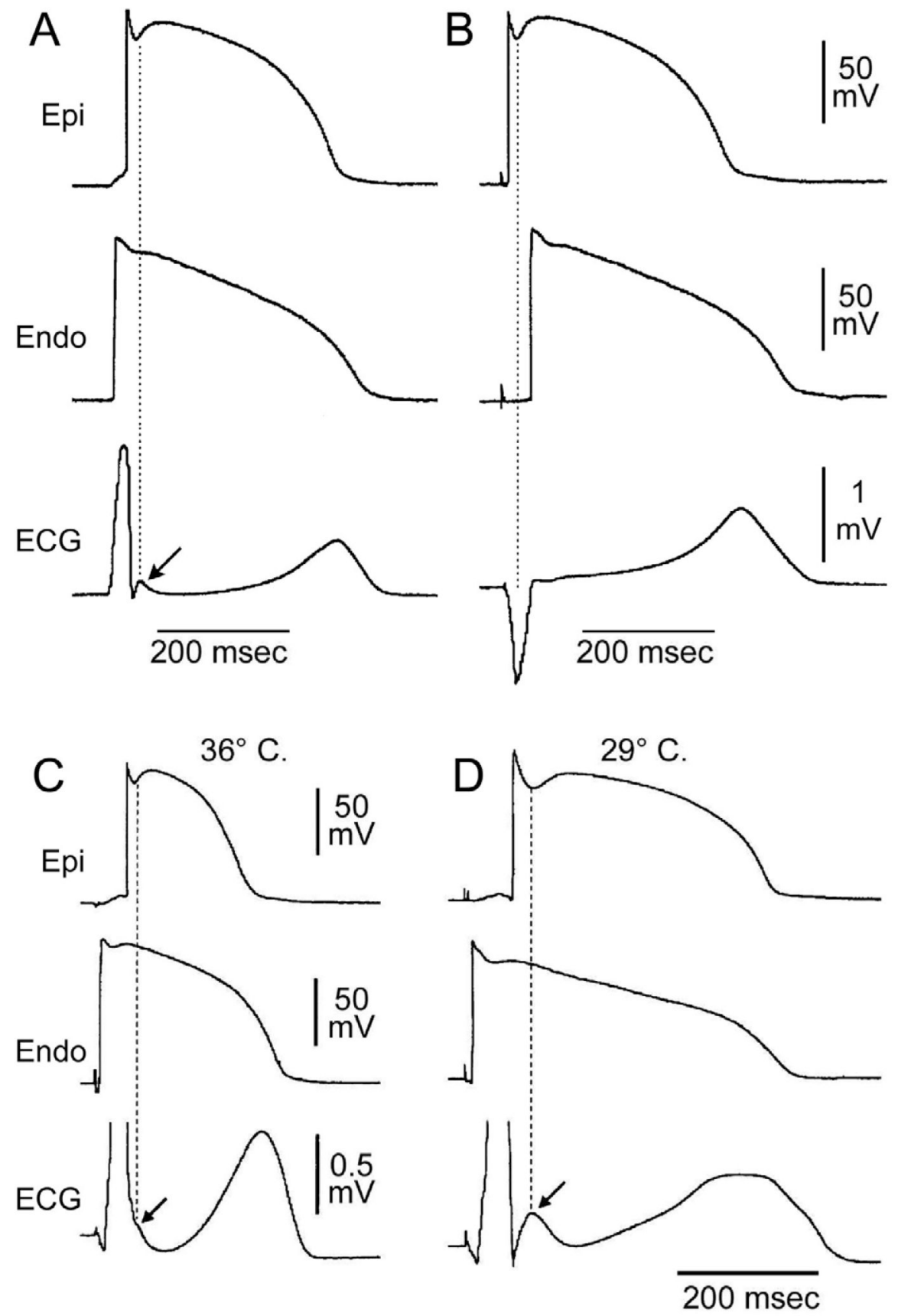

Figure 1.

Effect of ventricular activation sequence on the $\mathrm{J}$ wave on the pseudo-ECG recorded for a coronary-perfused canine right ventricular wedge preparation. A. When the wedge preparation is stimulated from the endocardial (Endo) surface with epicardium (Epi) activated last, a J wave on the ECG is temporally aligned with $\mathrm{I}_{\text {to }}$-mediated epicardial action potential notch. $\mathbf{B}$. When the preparation is paced from the epicardial surface with endocardium activated last, the epicardial action potential notch is coincident with the QRS, and a J wave is no longer observed (reprinted from Yan and Antzelevitch ${ }^{2}$ with permission). C: and D: Hypothermia-induced J wave. Each panel shows transmembrane action potentials from the epicardial and endocardial regions of an arterially perfused canine left ventricular wedge and a transmural ECG 
simultaneously recorded. C: Because of the smaller notch in the LV epicardium, a distinct $\mathbf{J}$ wave is not seen under baseline conditions. The small action potential notch in epicardium but not in endocardium is associated with an elevated J-point at the R-ST junction (arrow) at $36^{\circ}$ C. D: A decrease in the temperature of the perfusate to $29^{\circ} \mathrm{C}$ results in an increase in the amplitude and width of the action potential notch in epicardium but not endocardium, leading to the development of a transmural voltage gradient that manifests as a prominent $\mathrm{J}$ wave on the ECG (arrow). (Modified from Yan and Antzelevitch ${ }^{2}$, with permission) 

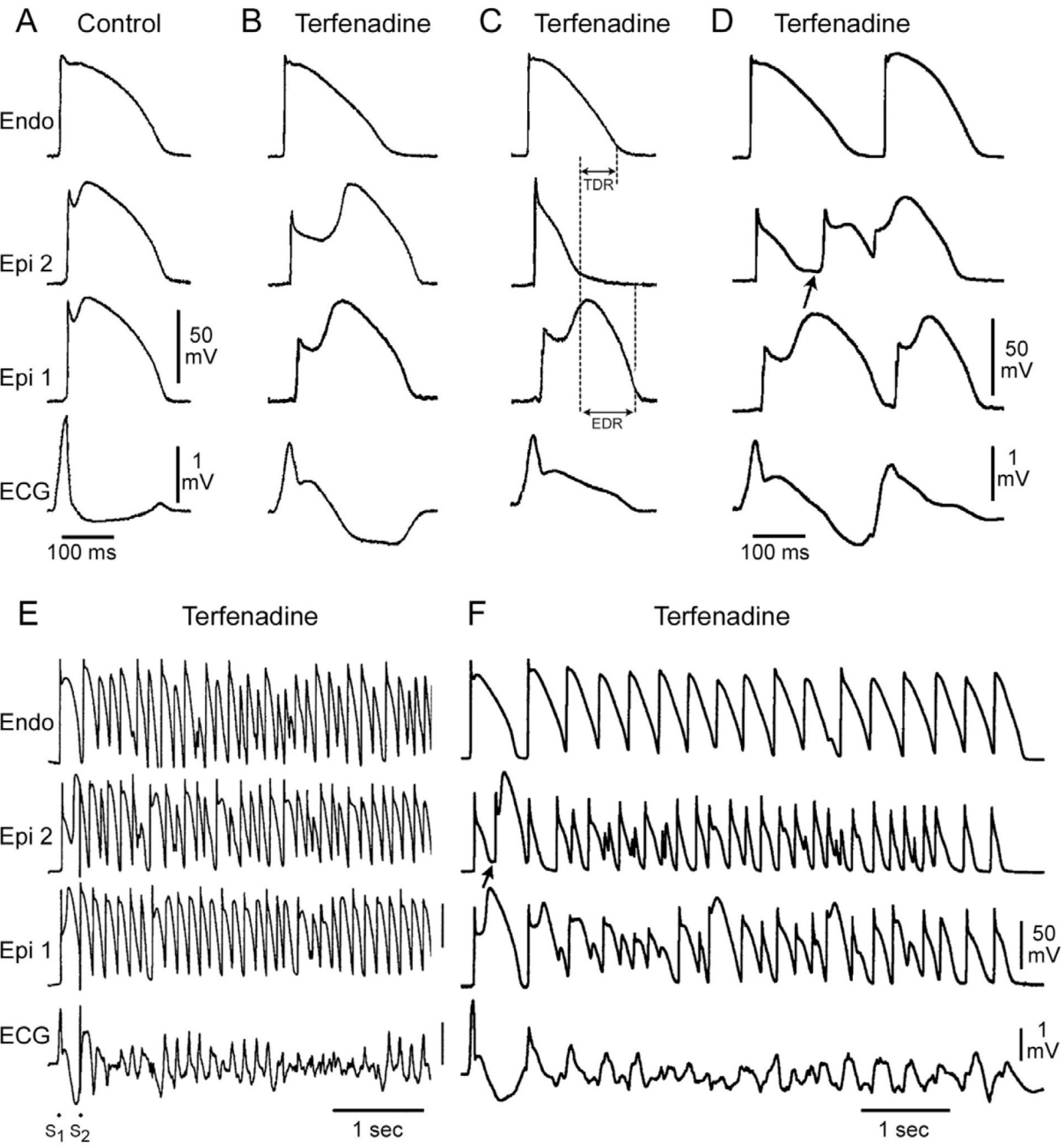

Figure 2.

Cellular basis for electrocardiographic and arrhythmic manifestation of BrS. Each panel shows transmembrane action potentials from one endocardial (top) and two epicardial sites together with a transmural ECG recorded from a canine coronary-perfused right ventricular wedge preparation. A: Control (Basic cycle length (BCL) $400 \mathrm{msec}$ ). B: Combined sodium and calcium channel block with terfenadine $(5 \mu \mathrm{M})$ accentuates the epicardial action potential notch creating a transmural voltage gradient that manifests as a ST segment elevation or exaggerated $\mathrm{J}$ wave in the ECG. C: Continued exposure to terfenadine results in all-or-none repolarization at the end of phase 1 at some epicardial sites but not others, creating a local epicardial dispersion of repolarization (EDR) as well as a transmural dispersion of repolarization (TDR). D: Phase 
2 reentry occurs when the epicardial action potential dome propagates from a site where it is maintained to regions where it has been lost giving rise to a closely coupled extrasystole. $\mathbf{E}$ : Extrastimulus (S1-S2 $=250 \mathrm{msec}$ ) applied to epicardium triggers a polymorphic VT. F: Phase 2 reentrant extrasystole triggers a brief episode of polymorphic VT. (Modified from reference Fish and Antzelevitch ${ }^{73}$, with permission) 


\section{A Early Repolarization Syndrome in a Healthy Young Male}

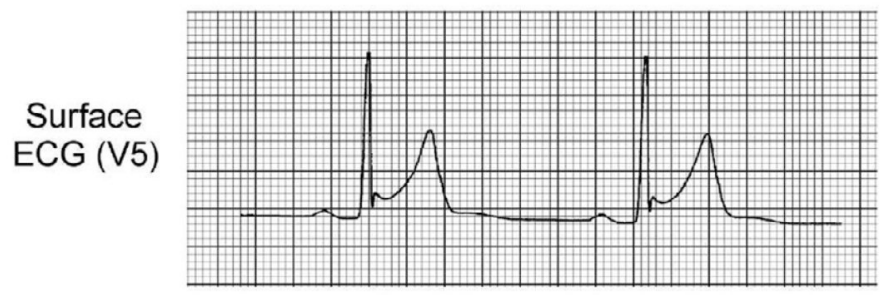

\section{B Canine Ventricular Action Potentials and ECG}

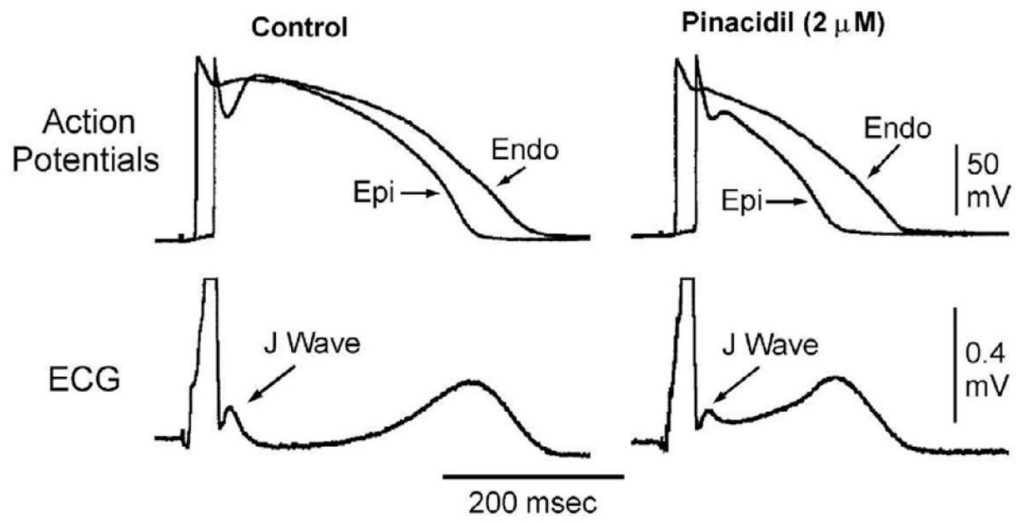

C
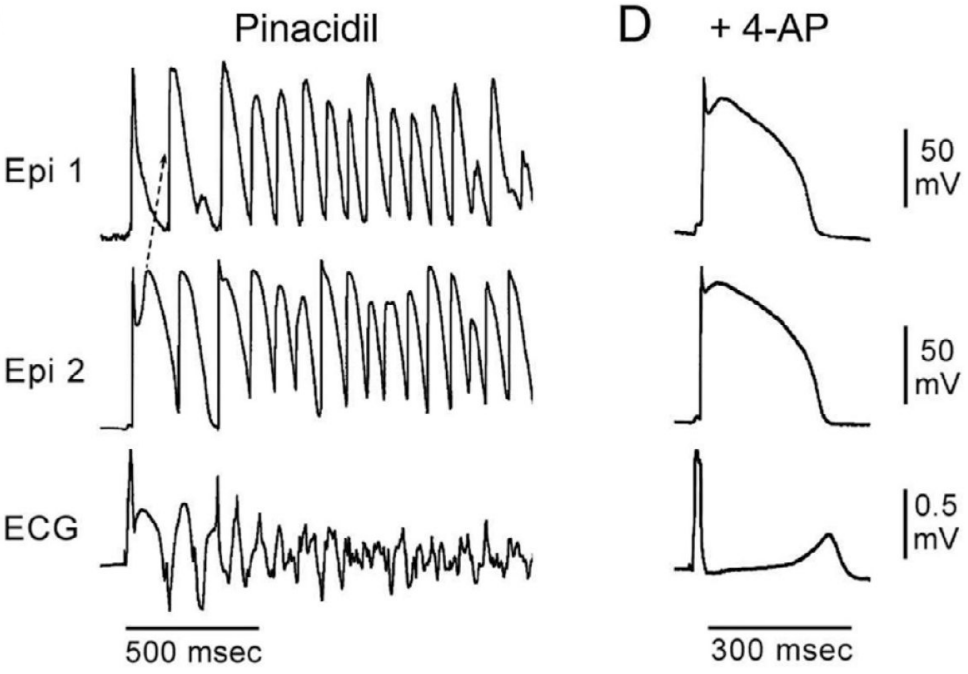

Figure 3.

Cellular basis for the early repolarization syndrome. A: Surface ECG (lead V5) recorded from a 17-year-old healthy African American male. Note the presence of a small J wave and marked ST segment elevation. $\boldsymbol{B}$ : Simultaneous recording of transmembrane action potentials from epicardial (Epi) and endocardial (Endo) regions and a transmural ECG in an isolated arterially perfused canine left ventricular wedge. A J wave in the transmural ECG is manifest due to the presence of an action potential notch in epicardium but not endocardium. Pinacidil $(2 \mu \mathrm{M})$, an ATP-sensitive potassium channel opener, causes depression of the action potential dome in epicardium, resulting in ST segment elevation in the ECG resembling the early repolarization syndrome. Reprinted from Yan et al. ${ }^{31}$ with permission. C: $\mathrm{I}_{\mathrm{K}-\mathrm{ATP}}$ activation in the canine 
right ventricular wedge preparation using $2.5 \mathrm{uM}$ pinacidil produces heterogeneous loss of the AP dome in epicardium, resulting in ST segment elevation, phase 2 reentry and VT/VF $(\mathrm{BrS}$ phenotype). D: The $\mathrm{I}_{\mathrm{to}}$ blocker, 4-aminopyridine (4-AP), restored the epicardial action potential (AP) dome, reduced both transmural and epicardial dispersion of repolarization, normalized the ST segment and prevented phase 2 reentry and VT/VF in the continued presence of pinacidil. (Modified from Di Diego et al. ${ }^{66}$, with permission). 


\section{A. J wave and Associated Ventricular Tachycardia in a Patient}

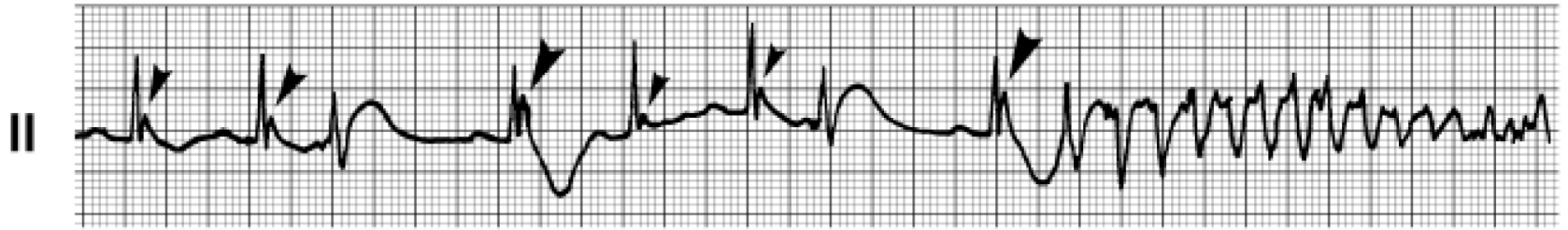

\section{B. Phase 2 Reentry and Ventricular Tachycardia in a Canine Ventricular Preparation}

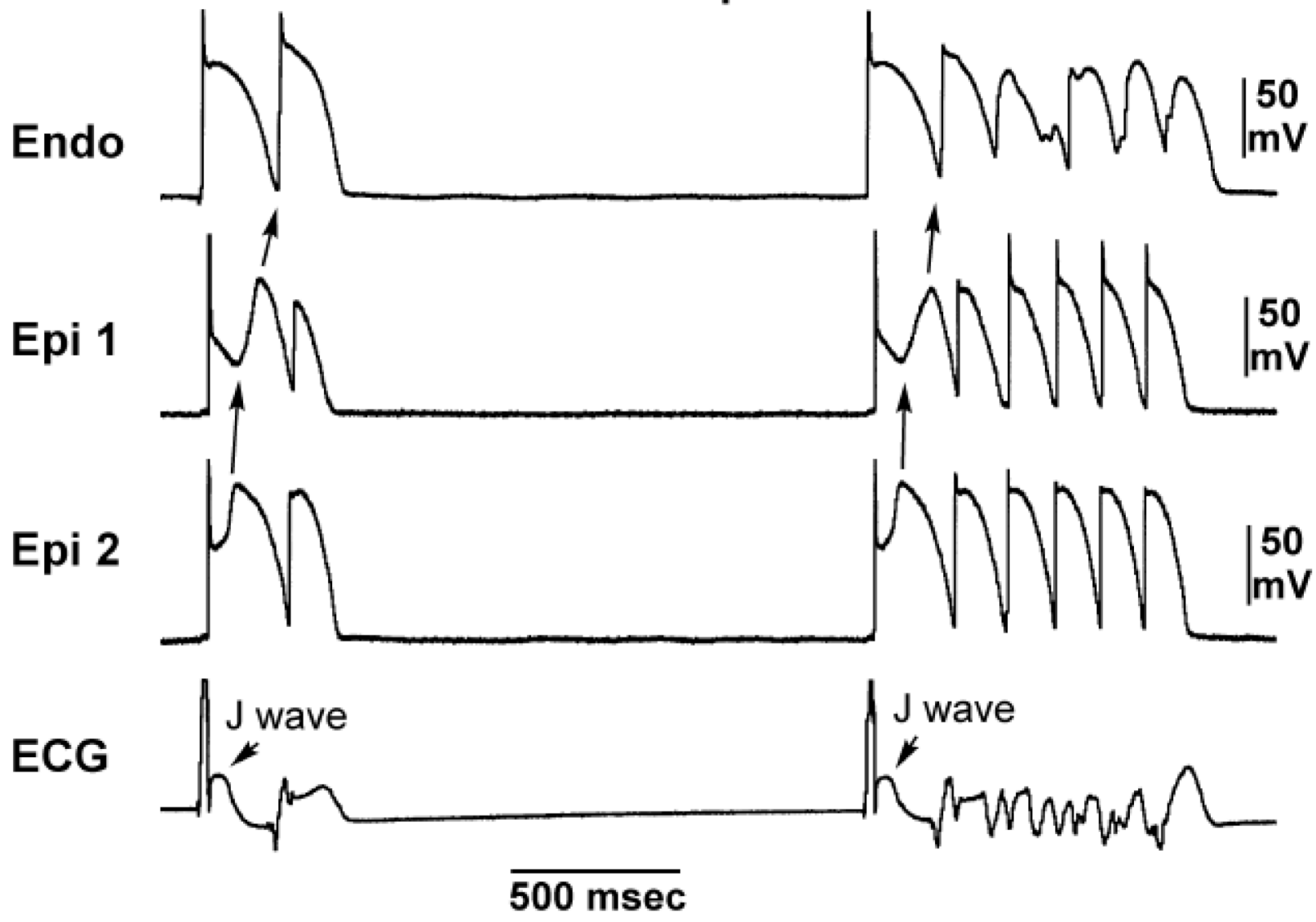

Figure 4.

J wave-mediated arrhythmogenesis. A: Development of VF in a patient with prominent $\mathbf{J}$ waves in lead II (reprinted from Aizawa et al. ${ }^{17}$, with permission). B: VF initiated by phase 2 reentry in a canine right ventricular wedge in the presence of $2.5 \mu \mathrm{mol} / \mathrm{L}$ of pinacidil. APs were simultaneously recorded from two epicardial sites $\left(\mathrm{Epi}_{1}\right.$ and $\left.\mathrm{Epi}_{2}\right)$ and one Endo site. Loss of the AP dome in $\mathrm{Epi}_{1}$ but not in $\mathrm{Epi}_{2}$ led to phase 2 reentry capable of initiating VF (modified from Yan and Antzelevitch, ${ }^{32}$ with permission). 

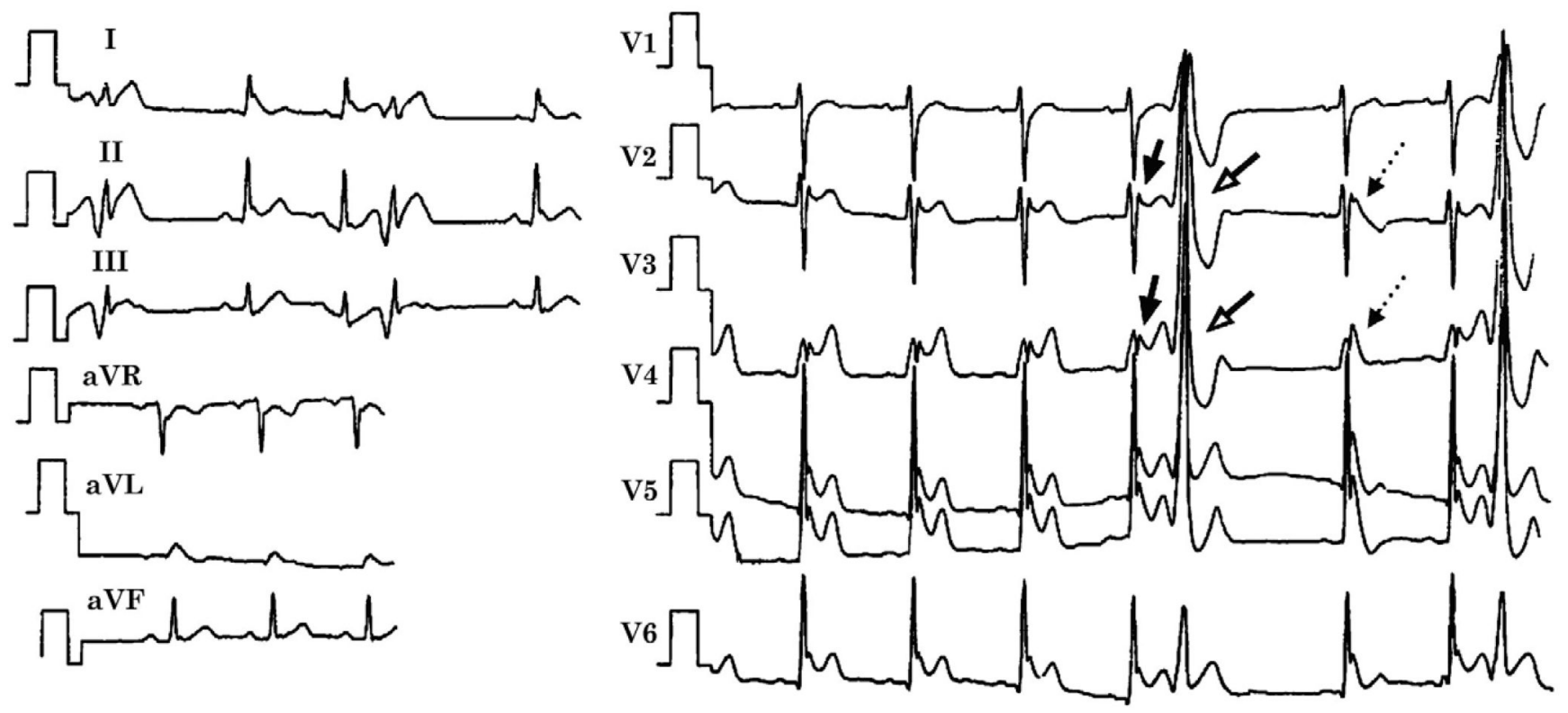

Figure 5.

ECG obtained from a 34-year-old Chinese man who survived cardiac arrest displaying characteristics of BrS , ERS and IVF. Prominent J waves and ST segment elevation are seen in almost all leads. The echocardiogram and cardiac catheterization, were normal. Prominent $\mathrm{J}$ waves and ST segment elevation were observed in almost all ECG leads, including an ER pattern in leads of I, II, aVL, aVF and V4 to V6 and a saddleback ST segment elevation suggestive of $\mathrm{BrS}$ in $\mathrm{V}_{2}$ to $\mathrm{V}_{3}$ (thick arrows). R-on- $\mathrm{T}$ extrasystoles, likely due to phase 2 reentry (open arrows) are seen and the post-extrasystolic beat displays a coved ST segment elevation characteristic of BrS (thin arrows). Reprinted from Qi et al. ${ }^{27}$, with permission. 
A. Dec. 191998
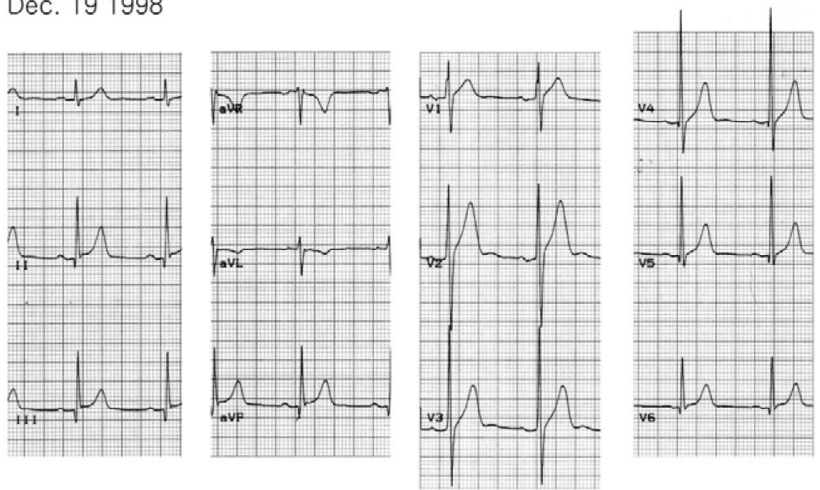

B. 6AM Aug. 182003
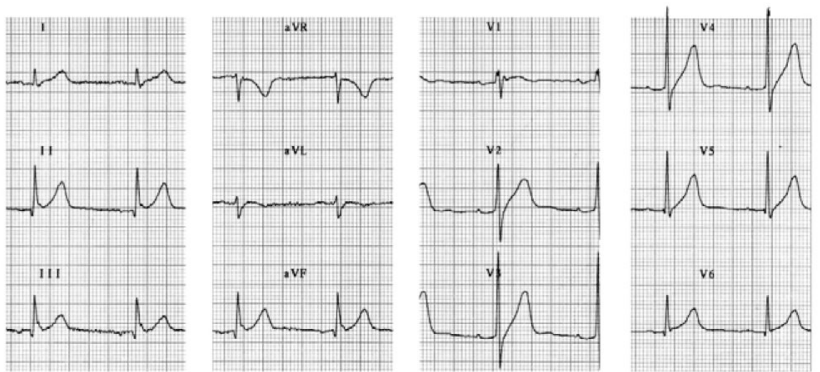

C. 10AM Aug. 182003
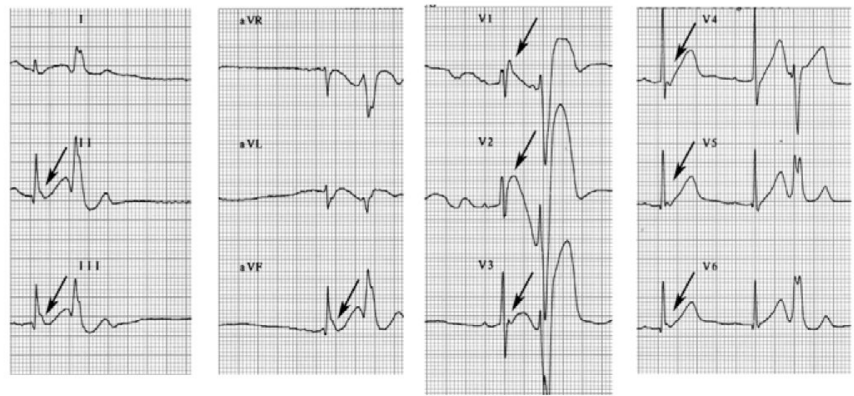

D. 10:46AM Aug. 182003

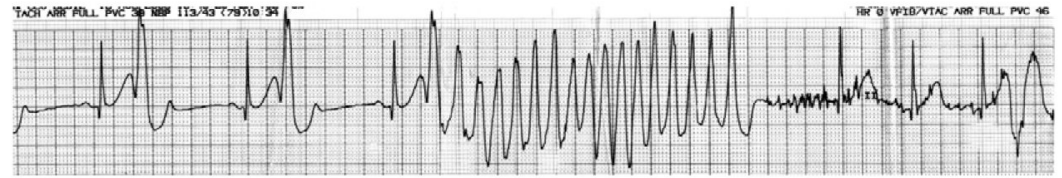

Figure 6.

Twelve lead ECGs from an ERS3 patient initially diagnosed with IVF. A: ECGs obtained on Dec 19, 1998 B: Recorded Aug 18, 20034 hours before the VF storm. C: ECG taken 10 minutes before VFT episode showing prominent $\mathrm{J}$ waves across the precordial and inferior leads (arrows) as well as prominent ST revealed more prominent $\mathrm{J}$ waves across the precordial and inferior leads (arrows) as well as an ST segment elevation in the right precordial leads giving rise to an R on T extrasystole. D: One of several episodes of non-sustained polymorphic VT. Arrhythmias were always initiated by extrasystoles with a short-long-short sequence (Modified from Nam et al. ${ }^{55}$, with permission) 


\section{Outward shift of repolarization current during early phase of the action potential} 工

\section{J Wave Syndromes}

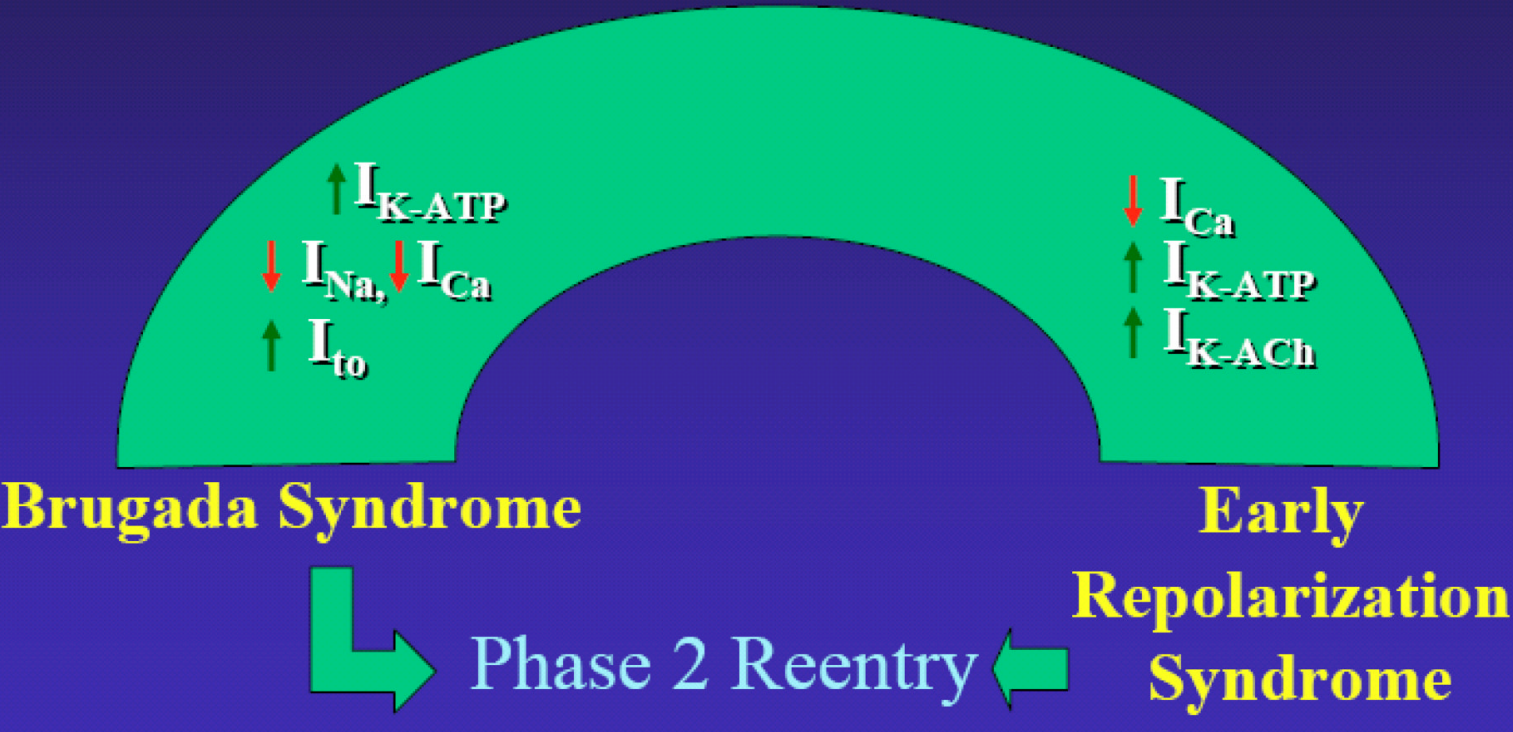

Figure 7.

J wave Syndromes. Schematic depicts our working hypothesis that an outward shift in repolarizing current due to a decrease in sodium or calcium channel currents or an increase in Ito, $\mathrm{I}_{\mathrm{K}-\mathrm{ATP}}$ or $\mathrm{I}_{\mathrm{K}-\mathrm{ACh}}$, or other outward currents can give rise to accentuated $\mathrm{J}$ waves associated with the BrS, Early Repolarization Syndrome and some forms of IVF. The particular phenotype depends on what part of the heart is principally affected and which ion channels are involved. 


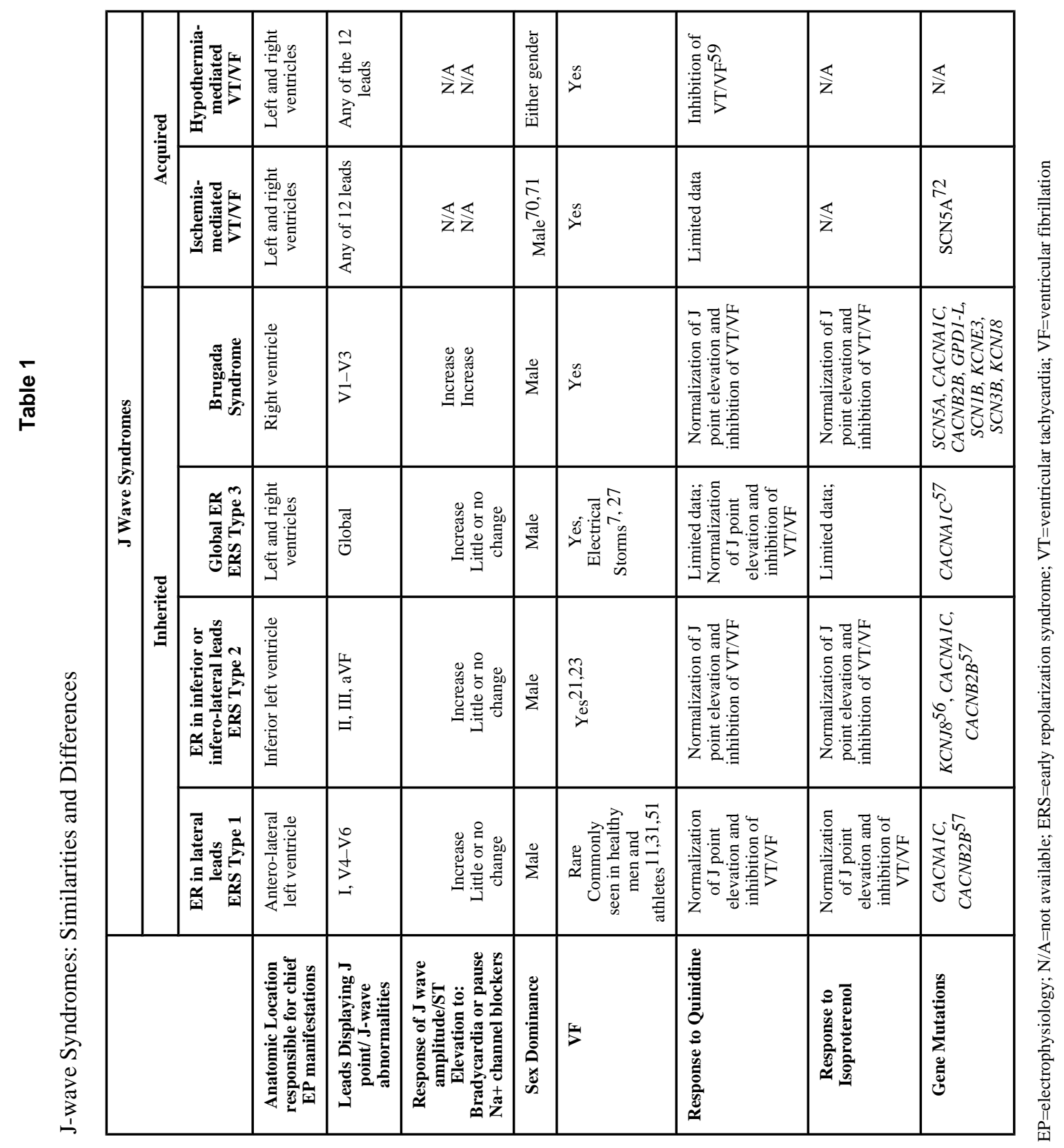

Heart Rhythm. Author manuscript; available in PMC 2011 April 1. 